\title{
Identificação de paleocanais na região da confluência entre os rios Ivaí e Paraná com o uso de dados de sensoriamento remoto e reconhecimento de fácies sedimentares
}

\author{
Eduardo Souza de Morais ${ }^{1 *}$, Manoel Luís dos Santos ${ }^{2}$, José Cândido Stevaux ${ }^{3}$
}

\begin{abstract}
Resumo No município de Icaraíma, noroeste do estado do Paraná, está localizada a confluência do rio Ivaí junto ao rio Paraná. Nesta área, ambos os sistemas fluviais promoveram o desenvolvimento de uma série de paleocanais que atestam a dinâmica quaternária da planície de inundação. Neste trabalho, propôs-se a aplicação de índices multiespectrais e uma transformação em dados do Landsat $5 \mathrm{TM}$, associado ao reconhecimento em campo e sondagens para associação de fácies sedimentares, a fim de serem identificados os paleocanais. A aplicação dos índices Normalized Difference Vegetation, Normalized Difference Water e Modificated Normalized Difference Water não apresentou ganhos satisfatórios. No entanto, a transformação Tasseled Cap Wetness proporcionou um relevante ganho de informação no reconhecimento das feições dos paleocanais. A partir dos resultados de sensoriamento remoto, foram realizadas sondagens com o objetivo de se conhecer as fácies sedimentares que compõem os paleocanais, as quais atestaram a veracidade da interpretação das imagens multiespectrais.
\end{abstract}

Palavras-chave: paleocanais; sensoriamento remoto; índices; fácies sedimentares; rio Ivaí.

Abstract The confluence of Ivaí and Paraná Rivers is located near Icaraíma town on Northwest of Paraná State. The confluence of Ivaí River together with the Paraná one is located near Icaraíma city on the Northwest of Paraná State. In this region, several paleochannels showed quaternary dynamic of Ivaí and Paraná Rivers floodplain. The aim of study was to apply multispectral indices and a data transformation of Landsat $5 \mathrm{TM}$ data, associated with fieldwork and sedimentary facies to identify paleochannels. The results of the Normalized Difference Vegetation, Normalized Difference Water e Modificated Normalized Difference Water indices did not show satisfactory gains. However, the Tasseled Cap Wetness has provided an important gain of information on recognizing paleochannels facies. Through the remote sensing results sediment cores were realized and the sedimentary facies showed its correspondence with remote sensing interpretation.

Keywords: paleochannels; remote sensing; indices; sedimentary facies; Ivaí river.

INTRODUÇÃO No estudo geomorfológico das planícies aluviais, o reconhecimento dos paleocanais (forma, extensão e geometria espacial) é um importante indicador para a análise acerca da evolução dos processos que construíram o sistema fluvial. A análise geomorfológica dos paleocanais e de seus depósitos fornece subsídios para estudos da paleogeografia, paleoidrologia e do paleoclima regional. A percepção em campo e o mapeamento das paleoformas da planície aluvial são, portanto, fundamentais. Porém, sua identificação é frequentemente dificultada por alterações posteriores ao seu abandono, decorrentes da própria dinâmica fluvial, ou mais recentemente, da ação antrópica. Ademais, a pequena variação altimétrica dessas formas da planície aluvial dificulta sua identificação.

Neste sentido, o uso das técnicas de sensoriamento remoto tem contribuído significativamente no estudo e na caracterização de ambientes fluviais, possibilitando-se a avaliação de extensas áreas e de locais com difícil acesso. $\mathrm{O}$ emprego dessa ferramenta tem avançado recentemente na discriminação das feições geomorfológicas de paleocanais e demais paleoformas, abrangendo diversos tipos de ambientes (Almeida Filho \& Miranda 2007, Rossetti 2010, Rossetti \& Valeriano 2007, Zani \& Assine 2011,

\footnotetext{
${ }^{1}$ Universidade Estadual Paulista - Unesp, Presidente Prudente SP; Universidade Estadual de Maringá - UEM, Maringá PR, Brasil.

E-mail: moraiseduardo@hotmail.com

${ }^{2}$ Universidade Estadual de Maringá - UEM, Maringá PR, Brasil. E-mail: mldsantos@uem.br

${ }^{3}$ Universidade Estadual de Maringá - UEM, Maringá PR, Brasil. E-mail: jcstevaux@uem.br

${ }^{*}$ Autor correspondente
} 
Hayakawa et al. 2010, Mantelli et al. 2009, Papillou et al. 2009). As abordagens e os métodos utilizados no reconhecimento da paleodrenagem são distintos, com o emprego de imagens multiespectrais, modelos digitais de elevação (MDE) e imagens provenientes de radares de abertura sintética (SAR).

$\mathrm{Na}$ utilização de imagens multiespectrais, Gilvear \& Bryant (2003) destacaram cinco fatores de inter-relação da radiação eletromagnética e a superfície dos sedimentos: umidade, matéria orgânica, textura, estrutura e óxidos de ferro. A relação existente entre a reflectância e a umidade foi maior, fator este que também é recorrente característica nos paleocanais da área em estudo deste trabalho. Outro importante indicador da feição geomorfológica dos paleocanais é a vegetação. Em decorrência do arcabouço geológico, sedimentologia e umidade, a cobertura vegetal nos paleocanais, geralmente, torna-se distinta dos demais ambientes encontrados nas áreas úmidas.

O processo de abandono dos canais e o consequente preenchimento sedimentar que promovem a construção da planície registram importantes características sedimentares do sistema fluvial. A formação dos tratos deposicionais, que compõem a planície, pode se apresentar bastante variada. Contudo, a análise da textura e o tamanho dos grãos apresentam-se como relevantes indicativos da proveniência dos sedimentos, além de expressar possíveis perturbações no sistema fluvial como, por exemplo, alternância climática e interferências antrópicas (Santos \& Gasparetto 2008, Santos \& Stevaux 2000a, b). A análise dos depósitos, por meio do conceito de fácies sedimentares, tem possibilitado uma melhor compreensão sobre os processos morfogenéticos de construção das planícies de inundação (Stevaux \& Souza 2004), o desenvolvimento de ambientes lacustres (Grenfeel et al. 2010) e o desenvolvimento dos processos pedogenéticos atuantes nos depósitos aluviais (BullingerWeber 2006).

Com o objetivo de verificar a resposta da umidade e da vegetação, o presente trabalho analisou essas características a partir de técnicas de sensoriamento remoto, as quais possam promover o melhor realce de paleocanais em imagens multiespectrais Landsat 5/TM, além de caracterizar as fácies sedimentares que compõem os paleocanais da planície dos rios Ivaí e Paraná.

\section{CARACTERIZAÇÃO DA ÁREA EM ESTUDO A confluência dos rios Ivaí e Paraná}

está localizada entre os municípios de Icaraíma e Querência do Norte, noroeste do estado do Paraná. Nesta área, na qual ocorre a junção desses dois sistemas fluviais, há ampla planície de inundação (planície Paraná-Ivaí). Essa unidade geomorfológica possui uma área total de $48 \mathrm{~km}^{2}$, sendo uma das unidades do curso inferior do rio Ivaí mapeadas por Santos et al. (2008).

A planície Paraná-Ivaí apresenta pronunciados paleocanais e registra também outras feições geomorfológicas, como leque aluvial, as quais remetem sua evolução durante o Quaternário (Morais et al. 2010). Diversos estudos têm sido realizados acerca dos processos geomorfológicos do sistema fluvial do alto curso do rio Paraná, sua relação canal-planície, sua evolução e sobre as mudanças dinâmicas, climáticas e neotectônicas (Rocha 2002, Stevaux \& Santos 1998, Souza Filho 1993). Algumas investigações, com o objetivo de compreender a geocronologia das feições geomorfológicas regionais, têm utilizado de métodos de datação para documentar o período ativo de paleocanais nos sistemas fluviais dos rios Ivaí e Paraná. Os resultados encontrados indicam que tais paleocanais permaneciam ativos durante o Neo-holoceno (Stevaux \& Souza 2004, Santos et al. 2008).

O curso inferior do rio Ivaí, $150 \mathrm{~km}$ finais até a foz, é encaixado e sinuoso com proeminentes diques marginais formados predominantemente por pelitos. A construção dos coesos diques marginais do rio Ivaí é resultante do predomínio do transporte de cargas suspensas, as quais aumentam-se gradualmente em direção à sua foz. Feições como espiras de meandros podem ser identificadas ao longo de sua planície, porém referem-se à pretérita dinâmica quaternária do sistema fluvial. Não são atualmente identificados processos de abandono de canais ou arrombamentos de diques marginais.

Apesar dos barramentos a montante (Usina Engenheiro Sério Motta) e a jusante (Usina de Itaipu), o trecho do rio Paraná, próximo à foz do rio Ivaí, apresenta-se como uma porção em que o canal ainda flui em condições naturais. O rio Paraná, nessa região, apresenta múltiplos canais com barras e ilhas, sendo que a maior parte do transporte de sedimentos do rio Paraná ocorre como carga de fundo. Ao contrário do rio Ivaí, o sistema do fluvial do rio Paraná apresenta cheia anual marcante e processos geomorfológicos, como rompimento de diques, com formação de crevasses (Orfeo \& Stevaux 2000) (Fig. 1). 


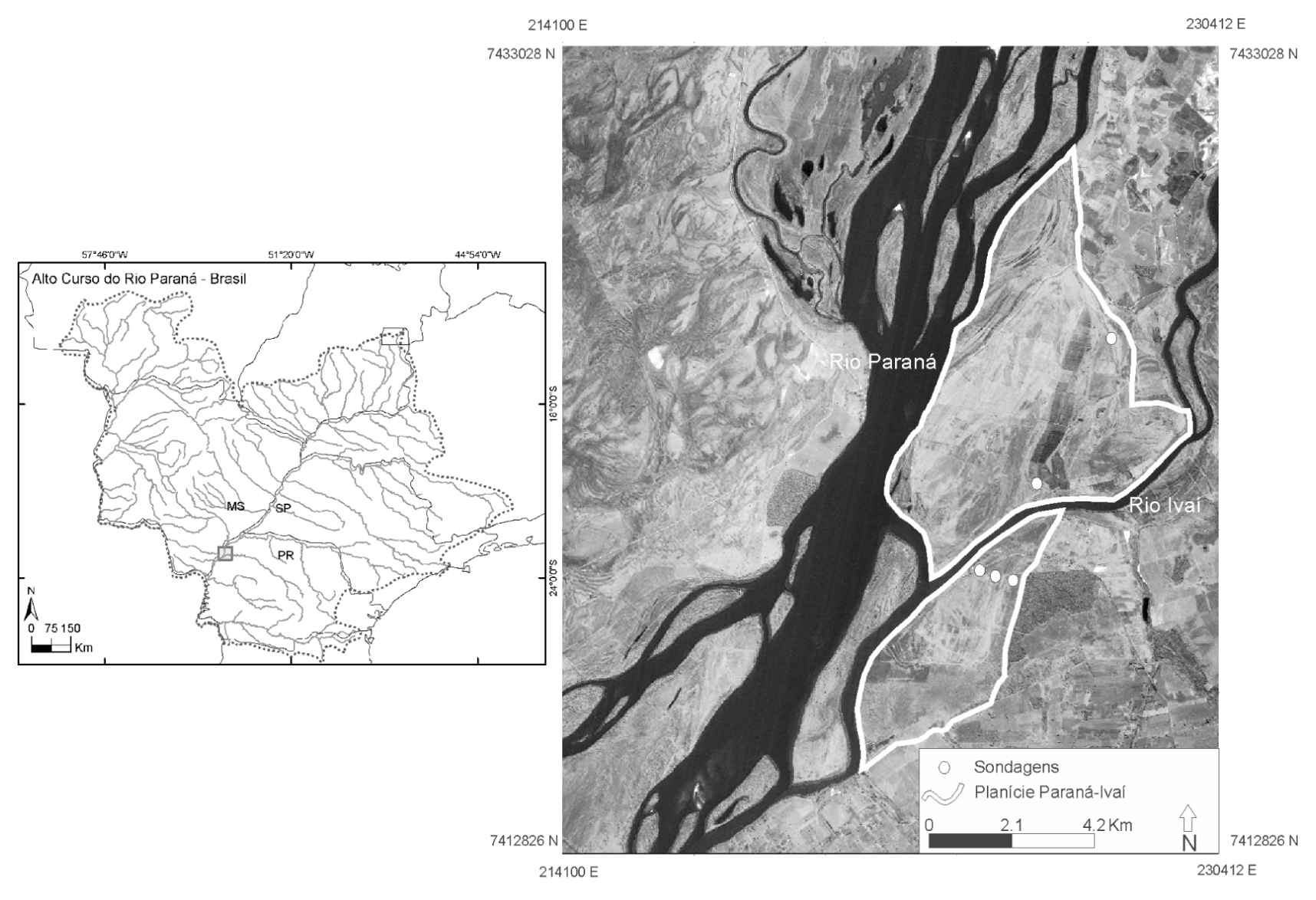

Figura 1 - Área em estudo, planície Paraná-Ivaí na região da confluência entre os rios Ivaí e Paraná, com a localização das sondagens efetuadas para reconhecimento dos paleocanais, imagem resultante da fusão Landsat/TM 5R 4G 3B e banda pancromática do CBERS 2/HRC.

MATERIAIS E MÉTODOS O estudo compreendeu sensoriamento remoto e levantamentos em campo para reconhecimento da planície e consequente aferição dos paleocanais identificados em produtos de sensoriamento remoto.

Para a aplicação das operações em imagens, utilizou-se uma cena referente à data de 11 de setembro de 1998 do sensor Landsat 5/TM, sendo as transformações dos valores digitais naqueles de refletância com a proposição utilizada por Gütler et al. (2005).

O mais conhecido índice de imagens multiespectrais e que possui ampla aplicação é o Normalized Difference Vegetation Index (NDVI). A partir deste, estudos de vegetação têm fornecido importantes resultados para o monitoramento da agricultura, das florestas e do meio ambiente (Jiang et al. 2006). O Normalized Difference Water Index (NDWI) foi aplicado para o delineamento de corpos d'água, com o uso dos canais verde e do infravermelho próximo, respectivas bandas 2 e 4 do Landsat 5/TM (Gao
1996). Com o objetivo de melhorar os resultados, eliminando-se os ruídos apresentados por meio da mistura espectral do solo com a água, obtidos pelo NDWI, Xu (2006) apresentou um modo alternativo com a modificação desse índice pela substituição da banda do infravermelho próximo usado no NDWI pelo médio (banda 5) do Landsat 5/TM, passando-se, assim, ao Modificated Normalized Difference Water Index (MNDWI). Outra proposta foi o uso da transformação Tasseled Cap. Essa operação consiste na transformação das seis bandas Landsat 5/TM (a banda 6 não é utilizada por sua resolução espacial de $80 \mathrm{~m}$ ), por meio de uma matriz de covariância calibrada para cada tipo de sensor, neste caso, o TM. Essa transformação produz três novos componentes: 'greenness', 'brightness' e 'wetness', sendo o último considerado em aplicações com o uso do fator umidade (Jin \& Sader 2005).

A partir do mapeamento dos paleocanais, fez-se o reconhecimento em campo da planície de inundação. Foram selecionados cinco pontos de amostragem 
para sondagem com o intuito de se reconhecer as fácies dos paleocanais. Utilizou-se, para isso, a sondagem à vibração (vibro core), precedida por trado mecânico. Os sítios de sondagens foram localizados com o uso de GPS de navegação. O estudo das fácies dos paleocanais revelou a dinâmica deposicional, permitindo-se inferir sobre a competência do canal e sobre o transporte e a deposição de sedimentos e reconhecer a direção principal do fluxo e a assembleia de minerais. A análise sedimentológica das amostras foi realizada utilizando-se o código de fácies proposto por Miall (1977), porém com a finalidade adotada por Santos (1997), “um corpo de sedimentos com características físicas (granulometria, estrutura, paleocorrente, geometria e matéria orgânica) próprias, porém distintas dos corpos adjacentes". A análise das fácies sedimentares visa identificar os processos atuantes na construção dos depósitos analisados e, assim, associá-los a morfologias características.

\section{DISCUSSÃO E RESULTADOS A dinâmica} dos distintos sistemas fluviais dos rios Ivaí e Paraná favoreceu a formação da planície Paraná-Ivaí. Essa área apresenta diversos paleocanais, alguns deles facilmente reconhecidos em fotografias aéreas e em levantamentos em campo. Entretanto, a dinâmica fluvial atual e o manejo do solo na planície acabam por mascarar estas feições. Com os resultados do sensoriamento remoto foi possível notar que os paleocanais assumem diversas direções, identificar regiões em que há truncamento e sobreposição dessas formas, denotando-se, portanto, diferentes estágios de evolução da planície Paraná-Ivaí. Os paleocanais na área em estudo apresentam tamanhos variados, contudo menores que os canais que compõem o sistema atual dos rios Paraná e Ivaí. Tratam-se de baixos topográficos, em certas localidades passíveis de reconhecimento em campo, e estão associados à vegetação característica das áreas mais úmidas da planície (Fig. 2).

A análise individual das bandas espectrais demonstrou que o intervalo da banda 5 do Landsat 5/TM proporciona melhor descriminação da umidade do solo. O maior destaque das áreas úmidas deve-se à baixa refletância dos corpos d'água nessa região do espectro (Jensen 2009). O índice NDVI apresentou maiores valores nas áreas em que a vegetação é mais exuberante (Fig. 3A). Como de seu propósito, a representação dos paleocanais é identificada pelas áreas com cobertura da vegetação menos exuberante.

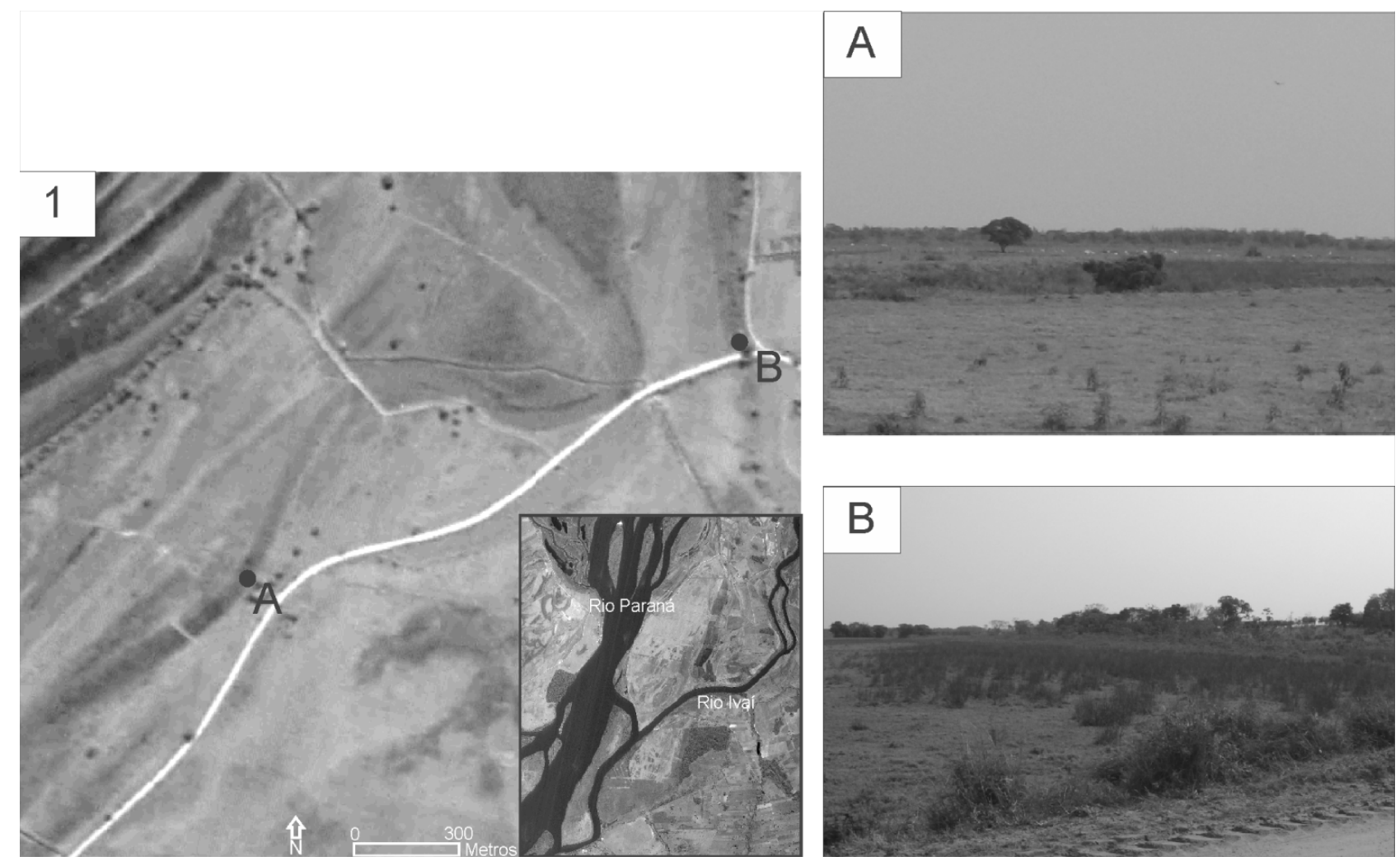

Figura 2 - As áreas mais escuras indicam a ocorrência de paleocanais na planície Paraná-Ivaí, imagem CBERS 2B/HRC. A e B mostram as áreas relacionadas aos paleocanais, que são caracterizadas por depressões topográficas em que se desenvolve vegetação de gramíneas associadas a este ambiente de maior umidade. 

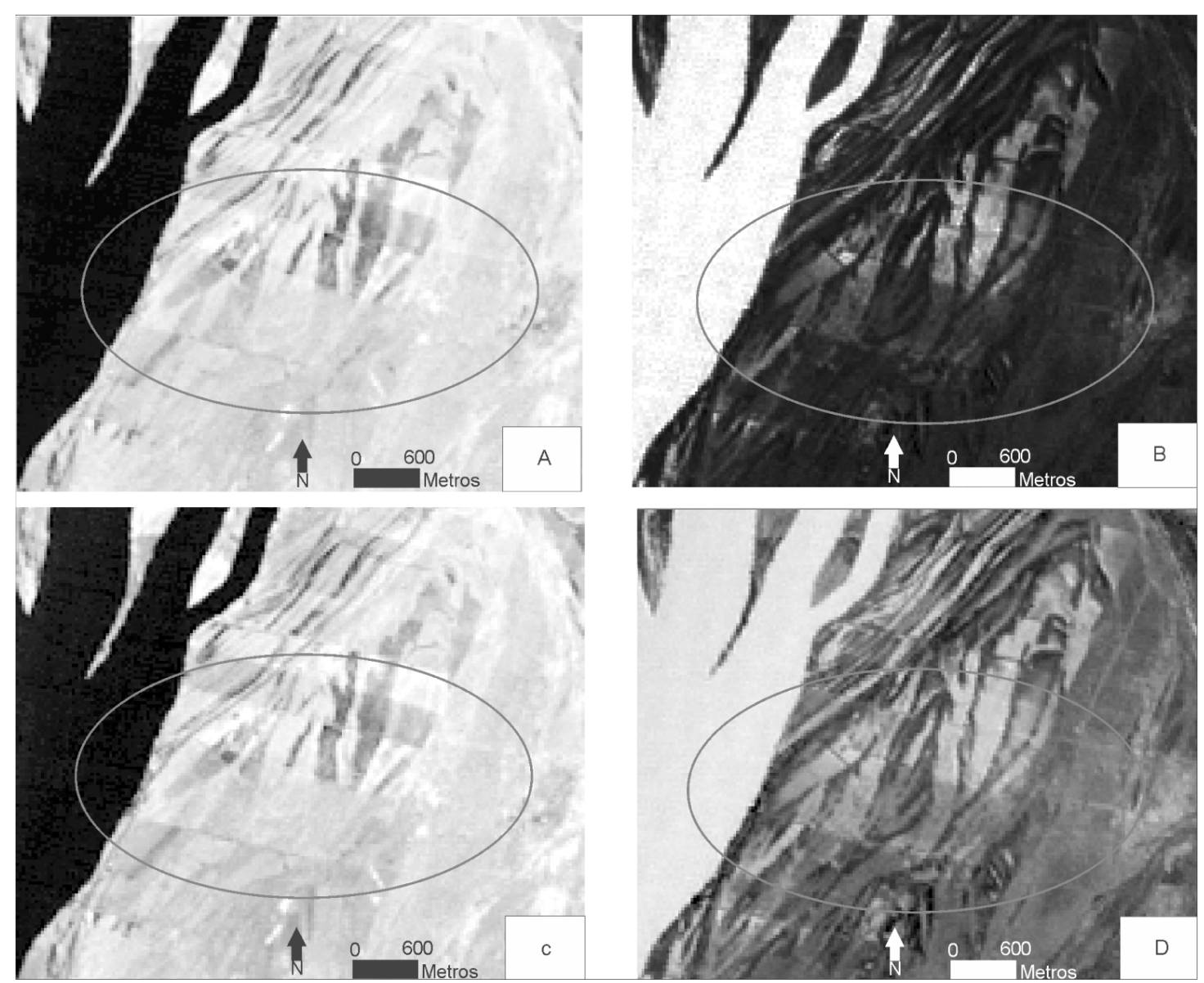

Figura 3 - O círculo destaca a área de ocorrência dos paleocanais com processamento das imagens Landsat, em: (A) aplicação do indice NDVI, (B) NDWI, (C) MNDWI e (D) a transformação Tasseled Cap Wetness.

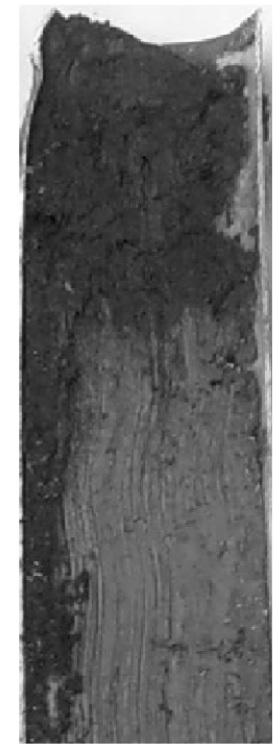

Fmo

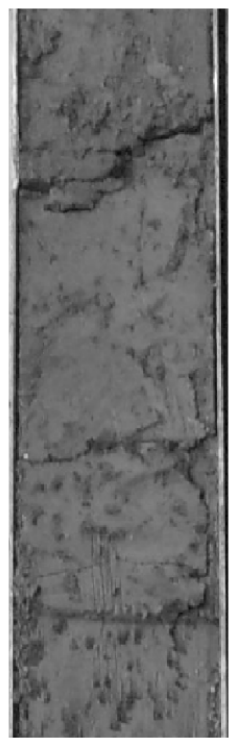

$\mathrm{Fm}$

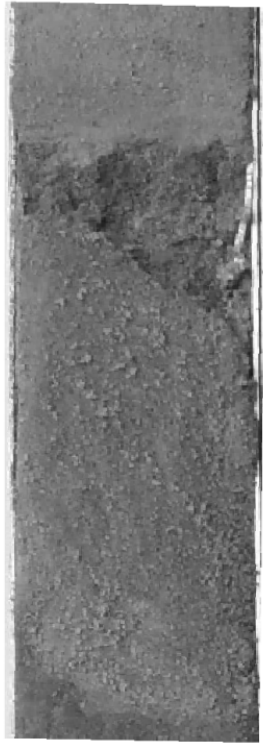

$\mathrm{Sm}$

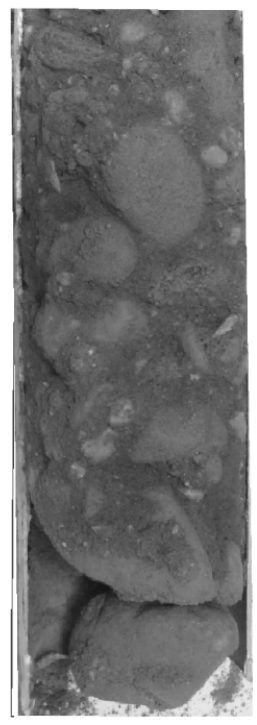

$\mathrm{Gm}$

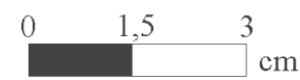

Figura 4 - Testemunhos de sondagem na planície Paraná-Ivaí, Icaraíma, no Paraná, sendo a fácies Fmo com presença de argila associada à alta concentração de matéria orgânica, fácies Fm com predomínio de material argiloso, fácies Sm em que ocorre o predomínio de areia e na base fácies Gm que possui cascalhos com matriz arenosa. 
A aplicação do índice NDWI, utilizado para o realce da umidade da superfície dos solos e sedimentos (Fig. 3B), demonstrou o ambiente da planície com realce pouco significativo dos paleocanais. Os valores mais altos de tal índice foram atribuídos a áreas úmidas contidas nas feições, porém, não é expressiva a sua relação direta com a morfologia dos paleocanais.

O índice MNDWI apresentou valores muito próximos ao NDVI, entretanto, com baixo alcance para o delineamento das paleoformas, com a não distinção das feições dos paleocanais (Fig. 3C). A relevância no tratamento dos dados Landsat é mostrada pelo emprego do Tasseled Cap Weteness, (Fig. 3D). O componente "Wetness", gerado por essa transformação, apresentou expressivo realce, permitindo uma ampla distinção dos canais que formam a paleodrenagem da planície Paraná-Ivaí. Provavelmente, o resultado deve-se ao uso de seis bandas do Landsat 5 , com três vezes mais quantidade de informações, sendo o ganho de realce superior ao de todos os outros procedimentos experimentados.

Com a identificação e o delineamento dos paleocanais, foram escolhidos cinco pontos de amostragem que pudessem melhor representar os ambientes de abandono da paleodrenagem. Neles, foram realizadas sondagens com espessura amostrada entre 2,40 e 4,05 m, na qual a análise dos testemunhos de sondagem possibilitou o reconhecimento das diferentes fácies e sua sucessão espacial e temporal (Fig. 4). Da base para o topo dos depósitos ocorrem fácies de cascalho $(\mathrm{Gm})$ com espessuras amostradas de até $0,5 \mathrm{~m}$, sucedidas pela fácies de areia fina à média $(\mathrm{Sm})$, que apresentam espessura entre 0,35 e $1,47 \mathrm{~m}$, e, finalmente, pelas fácies pelíticas (Fm e Fmo), as quais, em alguns pontos, alcançam até $1 \mathrm{~m}$. Esta nítida granodecrescência indica o abandono dos paleocanais da planície Paraná-Ivaí.

As fácies $\mathrm{Gm}$ são formadas por grânulos e seixos (com até $15 \mathrm{~cm}$ de diâmetro médio) maciços e representam ambiente fluvial com alta energia e alto potencial de transporte de sedimentos. Os cascalhos de vários calibres frequentemente apresentam matriz arenosa e fácies Gms. A passagem destas fácies basais para as arenosas que sucedem é abrupta. Mostram a perda da energia do paleocanal fluvial. As fácies ( $\mathrm{Sm}$ ) são formadas por depósitos de areia maciça, não estratificada e, pontualmente, apresentam baixa concentração de matéria orgânica. Representam uma fase em que o canal ainda era ativo, porém o aumento de material pelítico para o topo desta fase mostrou uma contínua perda de energia no sistema. A passagem desta fácies para as pelíticas é gradativa e reforça a interpretação da passagem gradual de um sistema lótico para lêntico, na evolução desta parte da planície aluvial, promovida pelo abandono do canal.

As fácies pelíticas maciças (Fm) e com matéria orgânica (Fmo) representam o estágio final do abandono do canal fluvial e o estabelecimento do ambiente da planície de inundação. Essas fácies são dominantes em toda a planície ParanáIvaí. São depósitos de silte e argila, com variável conteúdo de matéria orgânica. Os paleocanais, por serem áreas topograficamente deprimidas, com grande umidade e que, ocasionalmente, apresentam conexão com o canal atual do rio Ivaí, acumulam grande quantidade de matéria orgânica. Desenvolvem uma fácies de Turfa com cerca de 50 $\mathrm{cm}$ de espessura média, que dão aos depósitos uma tonalidade escura, ressaltada nas imagens. Tal fácies de turfa representa o último estágio de deposição na planície, refletindo-se a baixa energia do meio. Essas áreas, quando favorecidas pela topografia, promovem a manutenção de matéria orgânica em contínua decomposição.

CONSIDERAÇÕES FINAIS A utilização dos dados de sensoriamento remoto associados à análise de fácies sedimentares possibilitou a identificação e a caracterização das feições geomorfológicas de paleocanais relacionados aos rios Ivaí e Paraná. Os melhores resultados para a identificação de paleocanais, com o uso de imagens multiespectrais, decorreram do emprego do Tasselep Cap. Já os índices NDVI, NDWI e MNDWI não apresentaram bons resultados para o objetivo proposto. Na planície Paraná-Ivaí, o tratamento das imagens multiespectrais possibilitou identificar os paleocanais que não são definidos em imagens de alta resolução espacial e baixa resolução espectral, como as imagens do CBERS 2 B/HRC. As análises realizadas neste estudo mostram a importância da utilização do Tasseled Cap Wetness para o mapeamento de paleoformas.

As análises dos depósitos sedimentares dos paleocanais corroboram com a interpretação por sensoriamento remoto. As fácies sedimentares presentes nos paleocanais demonstram um gradual abandono da antiga drenagem, atestado pela presença de depósitos grosseiros de fácies de cascalho e areia, os quais 
eram superpostos aos de material argiloso com elevada concentração de matéria orgânica, associados ao ambiente atual de baixa energia.

Os resultados obtidos darão suporte para análise da evolução geomorfológica da planície Paraná-Ivaí. A adoção de estudos complementares futuros, como a datação dos depósitos da planície, provavelmente possibilitará a compreensão dos processos fluviais da planície e suas feições, além da inter-relação morfogenética entre a planície, os terraços e o leque aluvial.

AGRADECIMENTOS Os autores agradecem ao Conselho Nacional de Desenvolvimento Científico e Tecnológico (CNPq), pela concessão da bolsa de Mestrado ao primeiro autor e pela bolsa de produtividade em pesquisa aos demais. A Hiran Zani e Éricson Hayakawa pela revisão com sugestões e comentários.

\section{Referências}

Almeida Filho R. \& Miranda F.P. 2007. Mega capture of the Rio Negro and formation of the Anavilhanas Archipelago, Central Amazônia, Brazil: Evidences in an SRTM digital elevation model. Remote Sensing of Environment, 110:387-392.

Bullinger-Weber G. \& Gobat J.M. 2006. Identification of facies models in alluvial soil formation: The case of a Swiss alpine floodplain. Geomorphology, 74:181-195.

Gao B. 1996. NDWI - A normalized difference index for remote sensing of vegetation liquid water from space. Remote Sensing of Environment, 58:257-266.

GilvearD.J.\&BryantR. 2003.Analysis of aerial photography and other remotely sensed data. In: Kondolf G., M., \& Piégay H. (eds) Tools in Fluvial Geomorphology. John Wiley and Sons, Chichester, 688 p.

Grenfell S.E., Ellery W.N., Grenfell M.C., Ramsay L.F., Flügel T.J. 2010. Sedimentary facies and geomorphic evolution of a blocked-valley lake: Lake Futululu, northern Kwazulu-Natal, South Africa. Sedimentology, 57:1159-1174.

Gütler S., Epiphanio J.C.N., Luiz A.J.B., Formaggio A.R. 2005. Planilha eletrônica para cálculo de reflectância em imagens TM e EMT+ Landsat. Revista Brasileira de Cartografia, 57:162-167.

Hayakawa E.H., Rossetti D.F., Valeriano M.M. 2010. Applying DEM-SRTM for reconstructing a late Quaternary paleodrainage in Amazonia. Earth and Planetary Science Letters, 297:262-270.

Jensen J. 2009. Sensoriamento Remoto do Ambiente: Uma Perspectiva em Recursos Terrestres: Tradução de Epiphanio J.C.N. (coord.). 2. ed. São José dos Campos, Parêntese, 598 p.

Jiang Z., Huete A.R., Chen J., Chen Y., Li J., Yan G., Zhang X. 2006. Analysis of NDVI and scaled difference vegetation index retrievals of vegetation fraction. Remote Sensing of Environment, 101:366-378.

Jin S., Sader S.A., 2005. Comparison of time-series tasseled cap wetness and the normalized difference moisture index in detecting forest disturbances. Remote Sensing of Environment, 94:364-372.

Mantelli L.R., Rossetti D.F., Albuquerque P.G., Valeriano M.M. 2009. Applying SRTM digital elevation model to unravel Quaternary drainage in forested areas of Northeastern Amazonia. Computers \& Geosciences, 35:2331-2337.

Miall A.D. 1977. A review of the braided-river depositional environmental. Earth Science Reviews, 13:1-62.

Morais E.S., Cremon É.H., Santos M.L.D., Souza Filho E.E., Stevaux J.C. 2010. Orientação da drenagem como resposta a controles geomorfológicos: análise do Córrego Dourado, Paraná - Brasil. Boletim de Geografia, 28:127-135.

Orfeo O., Stevaux J.C. 2002. Hydraulic and morphological of the middle and upper reaches of the Paraná River (Argentina and Brazil). Geomorphology, 44:309-322.

Papillou P., Schuster M., Tooth S., Farr T., Rosenqvist A., Lopez S., Malezieux M. 2009. Mapping of a major paleodrainage system in Eastern Libya using orbital imaging radar: The Kufrah River. Earth and Planetary Science Letters, 277:327-333.

Rocha P.C. 2002. Dinâmica dos canais no sistema rioplanície fluvial do alto rio Paraná, nas proximidades de Porto Rico-PR. Tese de doutorado, Universidade Estadual de Maringá, Maringá, 83 p.

Rossetti D.F. 2010. Multiple remote sensing techniques as a tool for reconstructing late Quaternary drainage in the Amazon lowland. Earth Surface Processes and Landforms, 35:1234-1239.

Rossetti D. \& Valeriano M. 2007. Applying SRTM topographic data to characterize a Quaternary paleovalley in northern Brazil. In: Anais XIII Simpósio Brasileiro de Sensoriamento Remoto, Florianópolis, p. 2125-2132.

Santos M.L., Gasparetto N.V.L. 2008. Minerais pesados dos depósitos aluviais do Rio Paraná e sua implicação paleoidrológica. Pesquisas em Geociências, 35:71-81.

Santos M.L., Stevaux J.C., Gasparetto N.V.L., Souza Filho E.E. 2008. Geologia e geomorfologia da planície do rio Ivaí-PR. Revista Brasileira de Geomorfologia, 9:23-34.

Santos M.L., Stevaux J.C. 2000. Facies and architetctural analysis of channel sandy macroforms in the upper Parana river. Quaternary International, 72:87-94. 
Santos M.L., Stevaux J.C. 2000. Fácies e suas associações nos depósitos rudáceos na bacia hidrográfica do rio Paraná em seu curso superior: uma tentativa de classificação. Pesquisas em Geociências, 28:171-182.

Santos M.L. 1997. Estratigrafia e Evolução do sistema siliclástico do rio Paraná, na região de Porto Rico - PR. Tese de doutorado, Instituto de Geociências, Universidade Federal do Rio Grande do Sul, Porto Alegre, $246 \mathrm{p}$.

Souza Filho E.E. 1993. Aspectos da geologia e estratigrafia dos depósitos sedimentares do rio Paraná entre Porto Primavera (MS) e Guaíra (PR). Tese de doutorado, Instituto de Geociências, Universidade de São Paulo, São Paulo, 214 p.

Stevaux J.C., Souza I.A. 2004. Floodplain construction in an anastomose driver. Quaternary International, 114:55-65.
Stevaux J.C., Santos M.L. 1998. Palaeohydrologycal changes in the upper Paraná River, during the Late Quaternary: A facies approach. In: Benito G., Baker V.R., Gregory K.J. (eds). Palaeohydrology and environmental change. Wiley \& Sons, New York, p. 273-298.

$\mathrm{Xu}$ H. 2006. Modification of normalized difference water index (NDWI) to enhance open water features in remotely sensed imagery. International Journal of Remote Sensing, 27:3025-3033.

Zani H., Assine M.L. 2011. Paleocanais no megaleque do rio Taquari: mapeamento e significado geomorfológico. Revista Brasileira de Geociências, 41:32-47.

Manuscrito ID 24950

Recebido em: 08/11/2011

Aprovado em: 19/03/2012 